\title{
Metals for bone implants: safety, design, and efficacy
}

\author{
Narges Shayesteh Moghaddam ${ }^{1}$ Mohsen Taheri Andani ${ }^{1,3} \cdot$ \\ Amirhesam Amerinatanzi ${ }^{2} \cdot$ Christoph Haberland $^{1} \cdot$ Scott Huff $^{4}$. \\ Michael Miller $^{5} \cdot$ Mohammad Elahinia $^{1} \cdot$ David Dean $^{5}$
}

Received: 21 September 2015/Accepted: 5 August 2016/Published online: 6 October 2016

(C) Springer International Publishing Switzerland 2016

\begin{abstract}
Like most bone deficits, mandibular segmental defects may result from surgical reconstruction due to congenital deformity, tumor resection, other pathologies, senescence, trauma, or infection. The goals of mandibular reconstruction are to restore the mandible's function and normal appearance. Clinical methods to restore the mandible typically rely on bone replacement using some combination of bone tissue transfer and metal implants. This paper reviews the safety, design, and efficacy of metal implants in general and specifically for the repair of mandibular segmental defects. These problems include implant incorporation, implant failure mechanisms (e.g., stress concentration, stress shielding), corrosion and toxicity, infection, and muscle re-attachment. Finally, this paper presents the use of porous nickel-titanium (NiTi) implants for the repair of skeletal defects through the example of mandibular segmental defects. Resorbable magnesium, and porous and non-porous NiTi, immobilization hardware are also discussed. These materials
\end{abstract}

David Dean

David.Dean@osumc.edu

1 Departments of Mechanical Industrial and Manufacturing Engineering, University of Toledo, 2801 W. Bancroft St. MS 312, North Engineering 2045, Toledo, OH 43606, USA

2 Department of Bioengineering, $2801 \mathrm{~W}$. Bancroft, University of Toledo, Toledo, OH 43606, USA

3 Department of Mechanical Engineering, S.M. Wu Manufacturing Research Center, University of Michigan, Ann Arbor, MI 48109, USA

4 College of Medicine and Life Science, 2801 W. Bancroft St. Toledo, Toledo, OH 43606, USA

5 Departments of Plastic Surgery, The Ohio State University, 915 Olentangy River Road, Columbus, OH 43212, USA provide new options which may better match the material properties, and if they can be 3D printed, better match the shape of surrounding host tissue. These advances might reduce engrafted bone and metal implant failure and restore musculoskeletal function for the long term. Patient-specific hardware and grafting strategies might prove to be useful tools in determining both the patient's appearance and functional outcome following reconstructive musculoskeletal surgery.

Keywords Mandibular segmental defect - Bone fixation . Additive manufacturing $\cdot$ Stress shielding $\cdot$ Nitinol (NiTi) Resorbable metal (Mg alloy)

\section{Introduction}

This two-part review looks at new metal alloys and metal fabrication strategies that are likely to benefit future skeletal implant strategies. In the first part of this review [1] we surveyed implant metal alloys and part fabrication strategies from the point of view of standard-of-care implants for the mandible. Several implant systems were discussed in order to present general points about metallic implant incorporation, failure, optimal design, and new fabrication methods. The second part of this review begins with a look at the mechanisms by which metallic implants are incorporated into the surrounding host bone. We next review the most common reasons why off-the-shelf, as opposed to patient-matched, metallic implants fail. We discuss options to improve the design of these implants through both general and patient-specific changes in implant geometry and materials that can be used to create normative stress-strain relationships between the implants and surrounding tissues, relationships that would preserve 
host bone geometry and muscle mass over the long term. Finally, we review opportunities for the use of newly available metals, especially those that have desirable material properties that were previously unavailable for use in skeletal implants. These new metals also have the added benefit that they can be used in additive manufacturing processes to prepare patient-specific implants.

\section{Bone incorporation of, or fixation by, metallic implants}

Metals have unique and often useful bulk, surface, and biological properties, including biocompatible strain and heat transduction. Unlike polymers which are often intended to degrade by hydrolysis or erosion, metals degrade in the body by either oxidative corrosion or galvanic corrosion [2-4]. Additionally, due to the high mechanical strength and fracture toughness of metals, they are useful for load-bearing applications. However, there are currently no FDA-approved metallic implants that are intended to resorb. As discussed in Sect. 5 of Part 1 of this review, the possibility of resorbable metallic fracture fixation is the topic of much research activity $[5,6]$. However, in current standard-of-care metallic implants, it is uniformly desirable to reduce or eliminate both types of corrosion [7].

The majority of pure metals are not useful because they rapidly corrode and/or are not biocompatible $[8,9]$. As an example, stainless steel had been the most common material among the metallic implants due to the low cost and the ease of fabrication $[10,11]$. However, it has a high stiffness (i.e., about ten times greater than that of bone) which can lead to bone resorption due to stress shielding. Additionally, it can stimulate an inflammatory response where the oxide of stainless steel becomes conductive [12]. However, several alloys, especially stainless steel, titanium and magnesium alloys, provide all of the positive capabilities of metals with minimal or controllable corrosion. Ti-containing alloys, such as the commonly used surgical Grade 5 titanium (Ti-6Al$4 \mathrm{~V}$ ), present low density, a high strength-to-weight ratio, high biocompatibility, and form an oxide layer to which bone progenitor cells can strongly adhere. Magnesium has a density slightly less than bone and is able to function as an osteoconductive and biodegradable implant material in load bearing applications. It is important to control the high rate of corrosion to make it applicable for biomedical applications [13]. Nickel-titanium (NiTi, Nitinol) has the lowest modulus of elasticity among all biocompatible metals and has biomechanical properties similar to bone such as a low modulus of elasticity and superelasticity behavior [1]. It also can provide the additional properties of shape memory, force hysteresis, fatigue resistance, thermal deployment, kink resistance, and MRI-compatibility. We call attention to the most important aspect of the shape memory seen in NiTi, this effect occurs at body temperature (see Sect. 4 of Part 1 of this paper [1]).

Although it is much discussed by researchers, there is little clinical experience with the use of magnesium alloys in resorbable bone fixation devices. Currently, the only metallic implant alloys that have been shown to be biocompatible over the long term are cobalt-chromium and titanium alloys. There is however no long-term advantage for either of these alloys, including after chemical or other surface modifications, including in cements, other than texturing. Bone attaches more quickly to titanium alloys than to cobalt-chromium alloys [14]. However, surface texture, in the form of roughness and/or porosity, can improve implant incorporation [15].

\subsection{In vitro and in vivo evidence for solid and porous nitinol implant integration}

The stiffness of an implant can be reduced by adding engineered porosity $[16,17]$. This section highlights the benefits of added porosity in both NiTi and other Ti-alloy implants. NiTi is well understood in its common orthodontic wire and vascular stent applications, but there is little clinical data on its use in bone immobilization hardware. Several studies have seen vascular and cellular activities increase immediately after implanting porous $\mathrm{NiTi}$, which led to blood clot formation within the pores of the implant $[18,19]$. It is observed that after 4 weeks the first phase of bone ingrowth is completed and new trabecular bone can be observed in the pores of an implant [20]. The next phase of bone ingrowth includes the stress induced modeling and remodeling of bony spicules into trabecular bone (Fig. 1). This stage is affected by the implant's mechanical properties, especially its Young's Modulus. Kujala et al. [21] studied the effect of porosity on the osseointegration of porous NiTi implants in the rat femur. Three specimens with three different porosities and mean pore size were used. The results as summarized in Table 1 show that higher porosity leads to more surface area, which may then lead to more bone contact/integration. In the case of deep bone ingrowth into resorbable implants, interconnecting pores are needed to provide the space for vascular ingrowth, which is required for continued bone remodeling [22, 23]. Factors such as the stability and degree of micro-motion between an implant and the surrounding bone, porosity cross-sectional area, and the location of the attachment site to the bone (e.g., trabecular or cortical bone attachment) all affect implant integration $[21,22]$. Studies have shown that excessive relative motion between a bone and implant at their interface leads to ingrowth of fibrous connective tissue. The lack of connective tissue at the interface of host bone and implant can 


\section{Compact Bone \& Spongy (Cancellous Bone)}

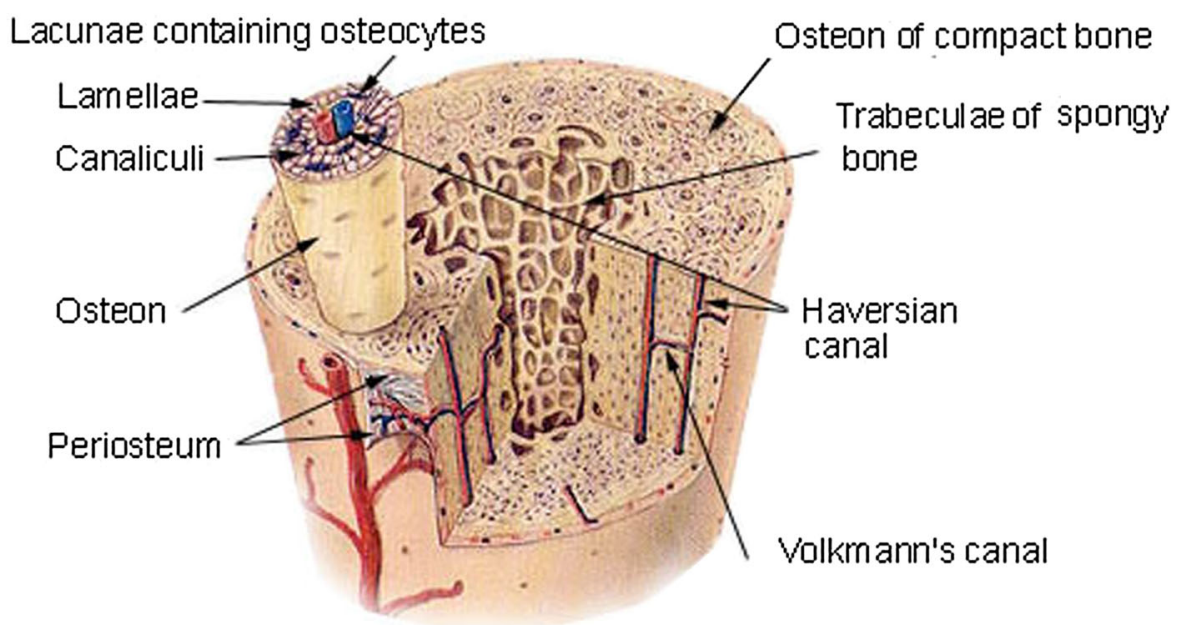

Fig. 1 Bone histology: note the distribution of strong (cortical) bone and the internal spongy (trabecular) bone. The trabecular bone seen to form initially on textured surfaces and in shallow pores on the surface of titanium implants is not well-suited to transduce the loads seen during walking in and around the major joints (i.e., hip, knee, and

Table 1 Characteristics of porous NiTi and mean bone contact/integration after implantation in the distal metaphysis of a rat femur for 30 weeks [21]

\begin{tabular}{llll}
\hline Measurements & $\begin{array}{l}\text { Group 1 } \\
(\mathrm{n}=14)\end{array}$ & $\begin{array}{l}\text { Group 2 } \\
(\mathrm{n}=4)\end{array}$ & $\begin{array}{l}\text { Group 3 } \\
(\mathrm{n}=15)\end{array}$ \\
\hline \% Porosity & 66.1 & 59.2 & 46.6 \\
\% Mean pore size $(\mu \mathrm{m})$ & $259 \pm 30$ & $272 \pm 17$ & $505 \pm 136$ \\
$\%$ Bone implant contact & $51 \pm 18$ & $29 \pm 13$ & $39 \pm 15$ \\
\hline
\end{tabular}

Values are given as a mean \pm standard deviation (SD)

lead to a lower level of integration and subsequently results in implant instability. Bruke et al. [24] experimentally showed that relative micromotion above $75 \mu \mathrm{m}$ leads to ingrowth of fibrous tissues. In another study they showed that a mixture of bone and fibrous tissue can be formed under relative motion of $40 \mu \mathrm{m}$. Kujala et al. [21] studied the variation in porosity of bone cross-sectional area and measured the subsequent bone-implant contact. They showed that an increase in the cross-sectional area of porosity from 46.8 to $64.5 \%$ can increase the interface connection between the bone and implant up to $75 \%$ [21].

Osseointegration of an implant can lead to better longterm fixation, good function, and biocompatibility (More discussion of osseointegration may be found in Sect. 3.4) [25]. Assad et al. [26] performed in vivo experiments that compared un-grafted, porous NiTi and non-porous, but otherwise standard, Ti-6Al-4V implants (i.e., "cages") in a mature sheep lumbar spine model for 3, 6, and 12 months. They did a quantitative analysis of osseointegration by spine). Cortical bone is better adapted to transduce these stresses. Recreating the normally occurring stress-strain trajectories through the use of metallic implants is a major challenge for the field of regenerative medicine. (Figure source: http://en.wikipedia.org/wiki/ File:Illu_compact_spongy_bone.jpg)

using radiological fusion outcome. Their results showed an increasing time-dependent trend of osseointegration from 22 to $38 \%$ in the case of using porous NiTi implants while porous Titanium (i.e., Ti-6Al-4V) implants showed less increase in bone osseointegration (23-25\%) [26].

Zhu et al. [22] implanted porous and bulk NiTi alloy constructs into a rabbit femur model for 15 weeks. In this study, no fibrous tissue was found at the interface between the implants and bone. This was interpreted as direct attachment of implant and bone. Additionally, histological microscopy confirms the interpretation of better osseointegration for the porous NiTi specimens than the bulk NiTi implants.

Another indicator of successful implant integration is bone apposition. Bone apposition, or appositional growth, is growth by addition of new layers. This indicates biocompatibility of the implant that leads to tissue-implant interface strength. Textured and porous materials in general show more bone apposition due to more surface area and more contact points. The in vivo experiments of Assad et al. [26] reported above, showed good bone-to-implant apposition with NiTi implants.

A cytokine release study can be used to investigate the presence of the toxicity caused by metallic implants. Habijan et al. [27] measured cytokine release for both porous and solid NiTi implants fabricated by the selective laser melting (SLM) 3D printing method. The specimens were cultured with autologous human Mesenchymal Stem Cells (hMSCs) and the cell activation was analyzed by detecting cytokine release. hMSCs were chosen for this study because they can be easily expanded in vitro and they 
Fig. 2 Histological images of porous NiTi and porous $\mathrm{Ti}$ after 15 weeks implantation. a The penetration of bone tissues into $\mathrm{NiTi}$ and also growth over the entire surface. $\mathbf{b}$ The good compatibility of Ti. c, d High magnification of 1 and 2 respectively. c The newly formed bone tissue inside and outer pores of porous $\mathrm{NiTi}$ and d as the same manner show this issue for Ti. [28]
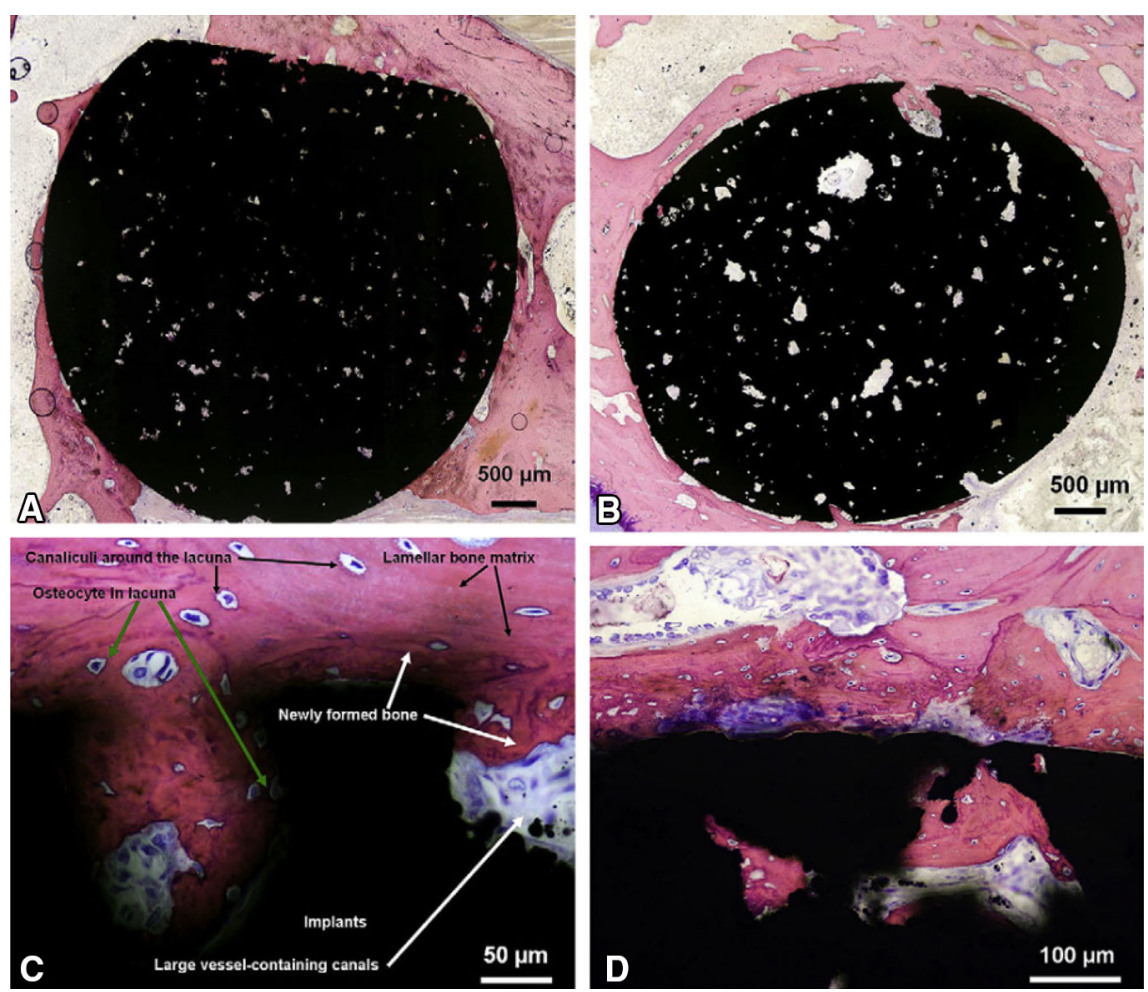

can be forced to differentiate into osteoblasts, chondrocytes, tenocytes and adipocytes; and, hMSCs maintain their stemness during expansion. Therefore, in the future, hMSCs may be a useful part of a cell-based therapy for bone deficit. Furthermore, hMSCs respond to cytotoxic influences such as Ni release from a NiTi implant. hMSC cell activation can be determined by the release of certain cytokines such as IL- 6 , IL-8 and VEGF in the presence of toxic levels of $\mathrm{NiCl}_{2}$ (i.e., nickel leached from the implant). Habijan et al. [27] observed that the cytokine release profile of samples with different surface morphologies and different amounts of porosity indicated no sign of cell activation due to $\mathrm{NiCl}_{2}$ toxicity. According to their results, nickel release is higher for the case of porous NiTi $(0.258 \mathrm{mg} / \mathrm{l})$ in comparison with that of dense NiTi samples $(0.027 \mathrm{mg} / \mathrm{l})$. Although the level of $\mathrm{Ni}$ release is shown to be increased for the case of porous NiTi, both porous and dense specimens are significantly lower than the cytotoxic level of $\mathrm{Ni}$ concentration (i.e., release of $25 \mathrm{mg} / \mathrm{l})$.

Liu et al. [28] used porous NiTi in an in vitro study, which resulted in cell growth on the surface of the material after 8 days of culturing. It was found that surface roughness and topography strongly affect cell attachment and proliferation. Histology from this study shows penetration of bone tissue into the surface of NiTi implants which is similar to other porous titanium implants (Fig. 2). In addition, Kujala et al. [21] observed that load bearing implants in rabbits presented
Table 2 Bone ingrowth into porous NiTi [29]

\begin{tabular}{lcll}
\hline Measurement & $\begin{array}{l}\text { Specimen at } \\
\text { 2 weeks } \\
(\mathrm{n}=10)\end{array}$ & $\begin{array}{l}\text { Specimen at } \\
\text { 4 weeks } \\
(\mathrm{n}=10)\end{array}$ & $\begin{array}{l}\text { Specimen at } \\
6 \text { weeks } \\
(\mathrm{n}=10)\end{array}$ \\
\hline \% Pore area & $57.3 \pm 5.7$ & $55.4 \pm 4.7$ & $55.8 \pm 6.4$ \\
\% Bone area & $6.6 \pm 2.2$ & $23.7 \pm 5.5$ & $44.2 \pm 10.5$ \\
\% Bone ingrowth & $11.3 \pm 2.7$ & $42.3 \pm 6.3$ & $78.3 \pm 9.7$ \\
\hline
\end{tabular}

bone tissue that did not penetrate more significantly into NiTi implants with increasing porosity from 46.6 to $66.1 \%$. These investigators concluded that a pore size of $50-500 \mu \mathrm{m}$ is optimal for bone tissue ingrowth under load bearing conditions. Kang et al. [29] performed a similar experiment in a rabbit model. Bone ingrowth into a porous NiTi implant increased over time (see Table 2). After 6 weeks this value reached $78 \%$.

One of the reasons for the NiTi implants demonstrating better ingrowth than Ti-6Al-4V implants is the high void volumes available for bone infilling [26, 30]. The pore interconnectivity and superelasticity of NiTi give the implant pump-like and capillary properties which cause absorption of surrounding fluid. These, in turn, provide the conditions by which bone progenitor cells and blood vessels can grow into the implant pores [22, 31, 32]. In other words, the capillary force controls the transport of fluid through the pore channels and on the other hand the material's wettability affects the velocity of fluid in its capillary spaces. This 
combination, capillary force and wettability, has been observed to allow bone penetration through the pores into internal structures of the implant [33]. Thus a porous NiTi implant is also more bioactive than bulk NiTi due to osteoblasts presenting good attachment and proliferation on the surface of textured and/or porous NiTi implants [22, 34] as well as the possibility of stiffness matching of the implant to the adjacent host bone [17].

\subsection{Magnesium-based resorbable metals}

$\mathrm{Mg}$ is a lightweight metal with a density slightly less than natural bone $\left(1.74\right.$ versus $\left.1.8-2.1 \mathrm{~g} / \mathrm{cm}^{3}\right)$ in ambient temperatures [1]. The major disadvantage of using $\mathrm{Mg}$ is its high corrosion rate in the body where it rapidly degrades; this limits its biocompatible applications [35-38]. If the corrosion rate can be controlled, $\mathrm{Mg}$ can be a good material for metallic implants because it presents a moderate elastic modulus of $45 \mathrm{GPa}$ that is similar to cortical bone and can help avoid stress-shielding effect [1].

One way to control the rate and timing of $\mathrm{Mg}$ resorption is to use other alloying elements in combination with $\mathrm{Mg}$. Recent studies have shown that non-toxic alloying elements such as $\mathrm{Ca}$ and $\mathrm{Zr}$ can significantly decrease the corrosion rate of $\mathrm{Mg}$ alloys [8, 39].

Another way to enhance the corrosion resistance of $\mathrm{Mg}$ alloys is to apply mechanical modifications including deeprolling and smoothing of micro-topologic surface features, and surface treatments such as plasma vapor deposition (PVD) and chemical vapor deposition (CVD) [40, 41]. PVD and CVD are the most common types for surface treatments and they are associated with the deposition of the vapor phase of protective components (e.g., atoms or molecules of the metal) onto the substrate [42-44]. In the CVD technique, during the deposition of solid material from vapor, a chemical reaction takes place. As an example, the diamond like carbon films can be deposited on a magnesium implant and enhance its biocompatibility features [45]. These techniques have been used to deposit several non-toxic and biocompatible alloy elements (i.e., $\mathrm{Ti}, \mathrm{Zr}$ and $\mathrm{Mn}$ ) on the $\mathrm{Mg}$. The results showed lower level of degradation of $\mathrm{Mg}$ which make it more suitable for biomedical applications [46, 47].

\section{Implant failure mechanisms}

Different reasons may contribute to the failure of metallic implants that are either caused by the material properties of the metal (e.g., high stiffness, high corrosion rate and toxicity) itself or by the exposure of the bone to infected metal implants (i.e., infection). In this section, we overview the common reasons for implant failure.

\subsection{Stress shielding and stress concentrations}

Bone changes its external geometry and internal structure in response to mechanical forces in a normal biological process known as bone remodeling. It maintains strength by modifying calcified tissue mass and geometric properties in response to the new demands placed by the loading conditions encountered by the skeleton. Bone remodeling is a continuous process that balances new bone formation and selective resorption, complementary processes that work together to optimize load-bearing function. In response to variation in local mechanical stimulus, bone forming cells (osteoblasts) or bone rebsorbing cells (osteoclasts) will be activated which effects bone turnover rate, density, and geometry. Under a new loading regimen, such as might be imposed following reconstructive surgery, the process will continue with highly active bone formation and remodeling rates until stress and strain levels return to normal [23].

Overly stiff implants alter the distribution of forces in the attached bone. The implant may shield parts of these surrounding bones from load and concentrate forces in other parts (e.g., at the site of fixation hardware screws). If stress-shielding reduces the load previously seen in areas around the implant, those areas may remodel in response, and that may lead to the total amount and density of bone tissue decreasing (osteopenia). This shielded bone will become anatomically smaller (external remodeling) and more porous (internal remodeling), thereby making it weaker. Additionally, if stress is concentrated in areas that have not previously been exposed to high loads there can be damage to the bone that results in fracture. This occurs when implants continuously transfer load too efficiently to areas that previously carried less strain. Stiffness-matched nitinol implants may mitigate this problem (Fig. 3) [48].

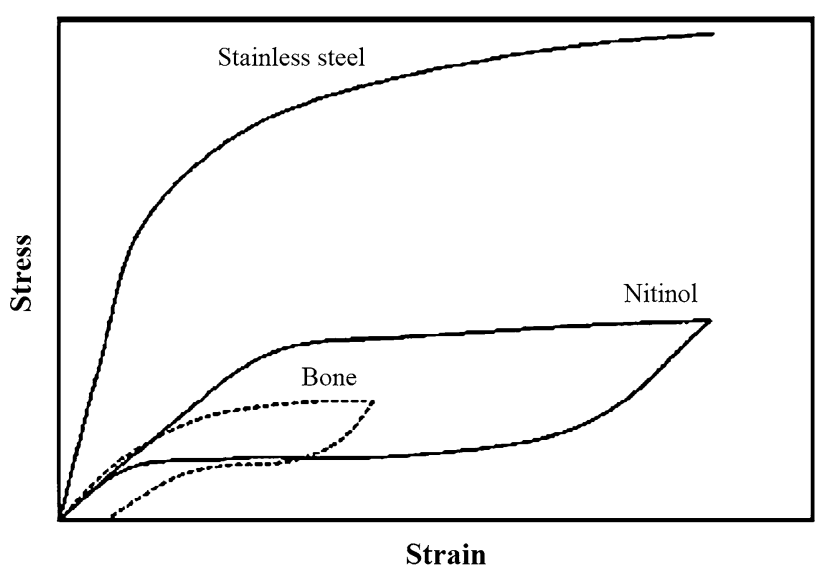

Fig. 3 Schematic stress-strain curves of stainless steel, NiTi, and bone [138]. 
Resorption resulting from post-implantation stress shielding and/or the damage resulting from abnormal stress concentration can contribute to the loosening of an implant [30, 49-53]. Loosening of an implant is the most common long-term complication of hip replacements. After the first 18 months post-surgery, the failure rate leading to revision after total hip arthroplasty is about $1 \%$ per year [54, 55]. Strain-adaptive bone remodeling theory can predict the amount of this bone loss or damage [20, 56]. To address stress shielding and/or stress concentrations, geometry and stiffness should be considered in the design of an implant.

The geometry of metallic implants has been observed to significantly change the distribution of stress that normally occurs in the replaced bone or bone segment such as in the femur following hip replacement. Most hip implants concentrate stress in distal regions of the diaphysis and transduce little stress to the proximal region of the femur where it is usually seen under normal conditions. This results in increasing bone density in the distal region which reduces axial stem displacement. It not only decreases the wedge effect of the stem within the diaphysis, but it also reduces the load on proximal regions. Therefore, bone in the proximal region of the femur starts to resorb and lose density (Fig. 4). To address this issue, the implant geometry must be designed to allow normal distribution of the load throughout the entire length of the cortex. That is, more of the compressive load must be transferred from the implant to the adjacent outer cortex, especially at the proximal end. If this can be achieved, the morphology of remaining cortical bone would be better maintained and

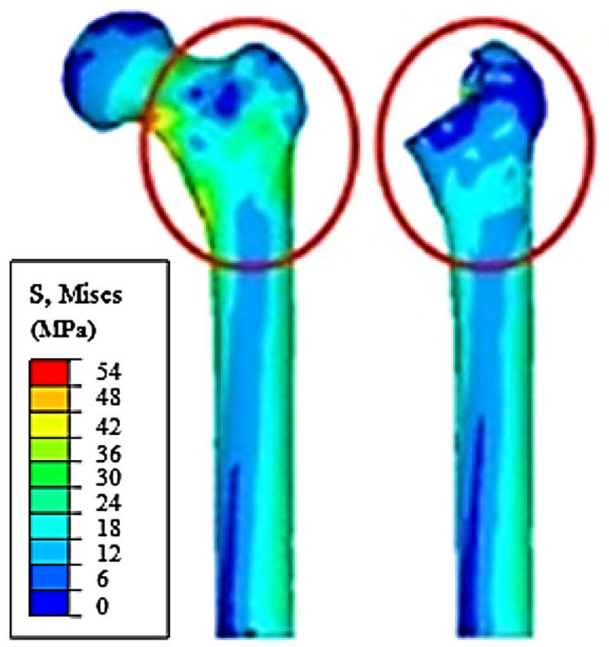

A Natural hip B Implanted hip

Fig. 4 Hip Implant Mechanical Environment. a Prior to implantation there is high strain medially just below the head and neck of the femur. b Following implantation strain is concentrated laterally near the greater trochanter and distally within the marrow cavity. c The normal loading pattern corresponds to the high density of bone seen superomedially just below the implant. d Bone density and cortical stress shielding would be diminished. One potential solution to this problem is an alternate geometry in which a shorter stem reduces shear stress along the implant-host bone interface. Using a more proximal junction may also distribute the load over more of the cortical cross section of the femur. As a result, stress shielding and interfacial shear stress (i.e., unhelpful stress concentration) could be decreased. Cables or other structures have been proposed in attempts to carry load from the implant to useful locations in the surrounding bone [20].

Even with optimized implant geometry, material stiffness mismatch, (discussed in Part 1 of this paper [1] and Shayesteh Moghaddam et al. [17]) with the surrounding bone can cause failure due to unhelpful stress shielding and/or stress concentrations [50]. A high stiffness ratio leads to high shear stress at the host/implant interface and reduced displacement in the surrounding bone [49]. A solution to reduce stiffness may be to add porosity to the implant. A porous surface has proven advantageous over tight-fitting smooth or cemented implants. Porous implants offer increased surface area and higher permeability that increases the level of osseointegration (see Sect. 2.1) [1, 57-59]. The reason that cemented implants are not as favorable is that they may transfer high levels of heat into the body which may cause harmful damage [60]. Additionally, they offer poor mechanical properties (e.g., tensile strength) which may lead to the loosening of an implant regardless of its design [61]. The appropriate surface texture, pore size, and pore connectivity may facilitate bone ingrowth, which would lead to higher strength of the

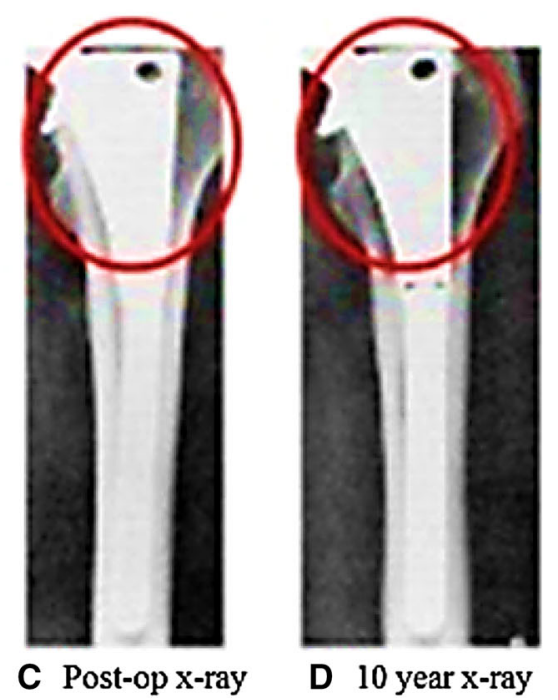

thickness increases in the distal marrow cavity in the 10 year postoperative X-ray. Note loss of density in the superomedial region (from: Dr. Andrew New, Director, Apogee Engineering Analysis Solutions Ltd, Hill House, Chapel Street, New Buckenham, UK, http://www.med-techinnovation.com/Articles/articles/article/11) 
implant-host interface. However, these surface features can only result in minor stiffness reduction [62]. In contrast, an implant with distributed porosity may demonstrate significantly reduced stiffness [17]. Additionally, the stiffness of porous materials can be altered and optimized by controlling the pore size, pore distribution and pore shape strategically during in the implant's design [63]. It is worth noting that an increase in porosity decreases the static and fatigue strength of an implant, which may be a useful tool in designing implants or implant components that provide a smooth modulus gradient across the host-implant interface.

\subsection{Corrosion and toxicity risk}

The corrosion properties of conventional implant alloys are well understood [64-66]. In this section, corrosion of the superelastic alloy NiTi is considered. NiTi corrosion can lead to release of $\mathrm{Ni}^{+}$ions, which in the human body is a potential long-term problem for these implants. Nickel is known to be carcinogenic and has been observed to cause allergic, cytotoxic, and mutagenic responses [67]. Ion release can also cause formation of a membrane around the implant (i.e., implant isolation or "foreign body response"), which prevents or disrupts the integration of the implant with surrounding bone tissue, a process that may lead to failure of the implant [68]. Based on conducted cytotoxicity, sensitization, and genotoxicity tests, it has been shown that solid NiTi implants do not induce cytotoxic, allergic, or genotoxic response nor any sign of cell lysis or diminishing of cell growth [69]. One reason for this is that solid implants have less contact surface than porous implants of the same external dimensions. However, a layer of passive oxide film $\left(\mathrm{TiO}_{2}\right)$ resists nickel release and corrosion [70].

The amount of nickel released from porous NiTi implants has been observed to be higher than in solid, nonporous material, perhaps due to the higher surface area [27, 70-73]. For porous implants and for applications where mechanical loading may damage the passivation oxide layer, additional surface modifications and coatings are possible solutions [69]. Techniques used to protect against nickel release include electrochemical treatments, chemical etching, heat treatments, ion implantation, laser and electron-beam irradiation, and a variety of coatings. The goal of these techniques is to create uniform, homogeneous and thick $\mathrm{TiO}_{2}-\mathrm{x}$ films, up to $\sim 30 \mu \mathrm{m}$, on all external implant surfaces [74].

Li et al. [31] conducted corrosion tests in order to find the effects of porosity on corrosion. Three different samples were used with porosity of 50.2, 55.1, and $60.4 \%$ rendered by a combustion synthesis method. These experiments were done at $37{ }^{\circ} \mathrm{C}$ in a constant temperature bath. The potentiodynamic polarization curves of porous NiTi with Hank's physiological solutions indicate that by increasing porosity, the corrosion resistance of porous NiTi is decreased. This is due to a larger surface area that results from pores [31]. Habijan et al. [27] performed experiments on porous and solid, non-porous NiTi specimens which were fabricated by Selective Laser Melting. Nickel ion release from these samples was analyzed in the cell culture medium using atom absorption spectroscopy. The results showed that nickel release from solid, non-porous NiTi was less than the porous samples, and that the amount of nickel released from both solid, non-porous and porous specimens was below cytotoxic concentrations [27].

If useful, surface modifications can reduce unwanted corrosion and toxicity risk in porous NiTi implants. Surface treatments have been reported to control nickel release and enhance implant performance. Successful surface treatments for NiTi implants include thermal annealing [75], plasma ion immersion implantation (PIII) [76, 77], and plasma vapor deposition (PVD) [73-75, 77, 78]. A limitation of these methods is that they may not reach all pore surfaces that would be in contact with the host's tissues via interstitial fluid. In order to modify surfaces of these internal pores, other treatments have been suggested such as chemical treatments [72, 79], PIII followed by chemical treatment [73], and in situ nitriding [70, 73, 75, 80, 81]. In order to determine nickel release before and after the surface modifications, NiTi may be immersed in simulated body fluid (SBF) solution. SBF's ionic concentration is similar to human blood plasma where the formation of apatite layers are expected to be accelerated [82].

\subsection{Infection}

To successfully integrate a metallic fixation device, host cells are needed to colonize the fixation surface. When planktonic bacteria such as staphylococci adhere to the surface of metallic devices they will compete with the host cells for colonization. Bacterial gene expression changes and the organisms surround themselves with a matrix containing protein and mucopolysaccharides that form a protective covering called a biofilm. Biofilms resist bacterial clearance by the host's natural defenses and antibiotics [83, 84]. It should be noted that bacteria can grow slowly or even remain dormant on metallic implants for several months to years with infection occurring suddenly once the numbers of bacteria reach sufficient levels to begin to invade the surrounding tissues [85]. By adding porosity to implants, larger surface areas within and around the implant are vulnerable to bacterial colonization $[85,86]$.

Removing biofilm is by no means easy. Therefore controlling and understanding the key factors that prevent bacterial adhesion is crucial in order to reduce the risk of 
infection [83]. Different factors contribute to the attachment of bacteria to an implant. These include surface topography, porosity, hydrophobic properties, intermolecular forces and local environment variables [87]. Because of all these risks (e.g., rapid corrosion, $\mathrm{Ni}^{+}$ion release, biofilm formation, etc.), most studies have concentrated on demonstrating effective surface treatments [83, 88-90].

\subsection{Implant loosening and osseointegration}

Implant loosening is a criteria for the failure of a reconstructive surgery and it can be predicted by the required level of torque for the loosening of the implant (more is better) [91-94]. Non-cemented implants are more stable than cemented implants. Cemented implants require reaming (via a drill) leading to removal of a higher level of bone in order to provide area for cement, and therefore a higher level of bone loss will occur. Additionally, the mechanical load transmitted to the surrounding bone is higher in the non-cemented implants [93].

For non-cemented implants, osseointegration is a crucial factor to avoid implant loosening. Branemark et al. [95] introduced the term of "osseointegration" for the first time to describe the direct structural connection between living bone and the surface of a load carrying implant [25].

Generally, NiTi is more flexible compared to surgical grade 5 titanium (Ti-6Al-4V) and it offers a higher level of deflection that helps the bone integrate with the implant. Liu et al. [28] showed more deflection $(0.3-0.85 \mathrm{~mm})$ on scaffolds prepared from porous NiTi than surgical grade 5 titanium, which ultimately led to deeper penetration of bone tissue to the porous scaffold. Additionally, their study revealed that the push-out force increased by $20 \%$ in the case of using porous NiTi over Ti-6Al-4V. In addition to introducing engineered porosity (Sect. 2.1), the osseointegration of implants can be enhanced with better surface properties (e.g., roughness and wettability).

The higher level of roughness in the surface of the implants promotes the osseointegration and leads to an increase in the removal torque and therefore lower risk for implant loosening [96]. Surface roughness can be created on an implant by various methods, such as metallic plasma spraying, blasting, acid-etching and anodizing. Buser et al. [96] measured the level of removal torque by calculating interface shear strength of unloaded titanium implants, with the same macroscopic shape but different surfaces roughness, inserted in the maxilla of pigs. Their results showed that a mean removal torque value is $0.13 \mathrm{Nm}$ in the case of using a machined surface. However, in the case of using sandblasted and titanium plasma-sprayed surfaces there was a significant increase in the mean removal torque (1.4 and 1.56, respectively). Elias et al. [97] also investigated the effect of surface treatments (e.g., sandblasting, acid etching and anodizing) on titanium implants. Based on their study, acid-etching causes more homogenous roughness on the surface and anodizing leads to smaller contact angles. Their results indicated that an anodized implant offers the highest removal torque value. These results were in agreement with the previous studies and showed that the level of roughness has a direct relationship with the removal torque value [97]. However, Albrektsson et al. [98] showed that the increased roughness of titanium causes removal torque increases up to a specific value (i.e., $1-1.5 \mu \mathrm{m})$ and after this critical amount, the removal torque decreases.

In addition to surface roughness, wettability (e.g., hydrophilic and hydrophobic) of the surface also can influence the mechanical properties at the interface of bone and implant. Hydrophilic surfaces can lead to better adsorption and adhesion of fibroblasts on the implant surface which promote implant osseointegration. In fact, the behavior of the proteins on the surface of an implant is dependent on their adsorption and adhesion to the surface. [99, 100].

\section{Patient-specific metallic implant design example: geometry and material properties for the reconstruction of mandibular segmental defects}

Tumor resection, infection (e.g., dental abscess), congenital abnormalities, trauma, or chronic inflammation can lead to mandibular segmental bone defects [101]. Left untreated, these defects can lead to airway obstruction, disfigurement, disturbance in speech and swallowing, and diminished masticatory ability. Surgical reconstruction methods are intended to restore the mandible's aesthetics and function, including restoration of bone continuity, muscle attachment sites, and stable dentition. None of the currently available clinical techniques meet all of the reconstructive requirements for the full restoration of form and function [102]. The treating clinician must select a specific technique based on a particular patient's needs [103]. Each method has certain advantages and disadvantages. For limited defects missing bone can be replaced using only a Ti-6Al$4 \mathrm{~V}$ bar to bridge the gap. The repair can be supplemented by adding allograft bone (i.e., bone tissue harvested and processed from a different patient) that is attached to this immobilizing bar and allowed to gradually heal in place (Fig. 5). Patient-specific implant bars have been shown to increase facial symmetry and aesthetic outcome in patients undergoing mandibular resection for malignant oral tumors [104-108]. High-resolution CT imaging and 3-D printing were used to produce models of the individual patient's mandible. The fixation bar is then contoured around the 


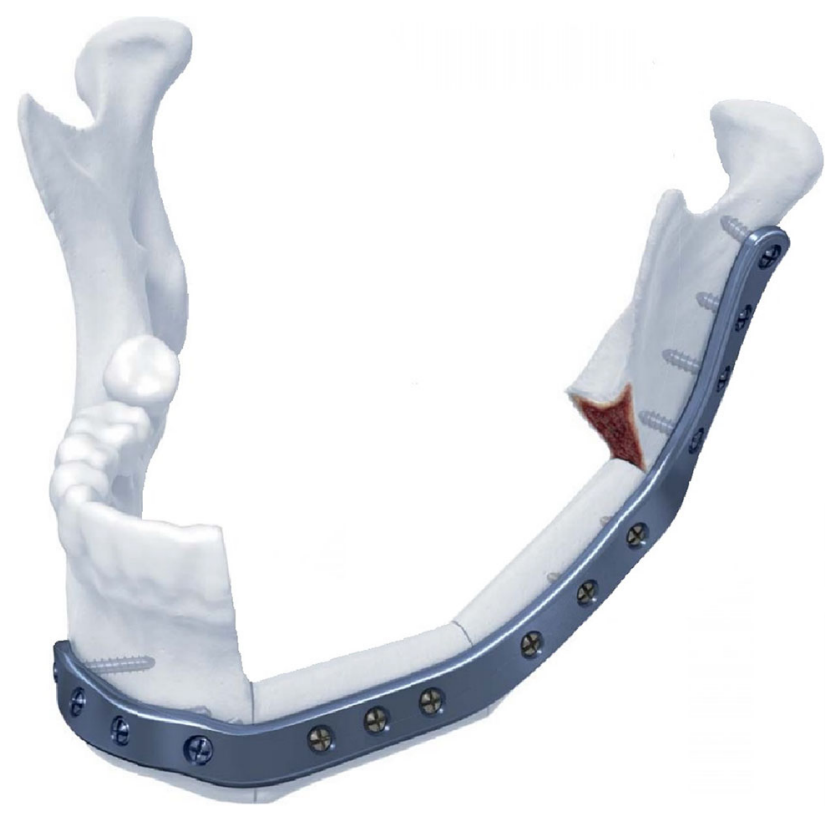

Fig. 5 Standard-of-Care Reconstruction of Mandibular Segmental Defect. (Source: http://www.synthes.com/sites/NA/NAContent/Docs/ Product\%20Support\%20Materials/Technique\%20Guides/MXTGPSP MandibleJ11954A.pdf)

model prior to reconstructive surgery. Post-surgically mandibular contour symmetry is evaluated and has been observed to be significantly higher in patients receiving a patient-specific implant bar. The use of semi-rigid mesh as a substitute for these rigid plates has also been suggested as an alternative procedure due to improved cosmetic appearance, the use of fewer screws, and a shorter surgical procedure [109, 110]. Either procedure allows the muscles to begin working immediately following surgery. This is critical for the rehabilitation of mastication, speech, normal breathing, and swallowing. The junction between the remnant host mandible and the newly engrafted bone is immobilized allowing the grafted and host bone to fuse.

In larger defects that are associated with deficient soft tissues as well as bone, vascular autologous bone transfer is the preferred method, with reports of successful bone incorporation in up to $95 \%$ of cases compared to methods using non-vascularized bone graft [110-113]. Transferring autologous bone (i.e., bone obtained directly from the patient) with an intact blood supply makes the healing period shorter and more reliable, reducing complications such as bone resorption, infection, and non-union [114]. For patients who cannot tolerate the long surgeries usually associated with vascularized bone transfer, the procedure can be staged. The initial operation is to prepare the soft tissues and remove the defective bone, which is replaced by a temporary spacer made of a non-deformable material (e.g., acrylic) [115]. After the patient heals from this procedure the second operation removes the spacer and transfers the bone. The fibula is the most common site for vascularized bone harvesting because it offers an adequate length of bone and is associated with low post-operative morbidity (i.e., health problems caused by bone harvest) and pain. The distance between the fibula and mandible also allows for two surgical teams to operate simultaneously decreasing the length of surgery. The principle disadvantage of the fibula for mandible bone replacement is the lack of the necessary height and width for reliable placement dental restoration in many patients. In these cases bone must be added by splitting the fibula into two pieces [116], by using distraction osteogenesis, or placing conventional non-vascularized bone grafts [117]. Iliac crest is another option for bone harvesting when the defect is less than half of the mandible or when greater mandibular height is mandatory [118]. Alloplasts are implants made from foreign material, such as titanium. Advantages include availability for immediate reconstruction, decreased surgical time compared to autologous bone grafts, and reduction in donor site morbidity [119].

There are unfortunately some recurring clinical problems associated with current reconstructive techniques for mandibular segmental defects. These are discussed in the following three sections:

\subsection{Stress shielding and stress concentration risk for a mandibular implant}

Stress shielding is a major concern when rigid immobilization plates remain permanently implanted [120]. For example, if the immobilization hardware is left in the patient following the attachment of crowns to dental implants (i.e., titanium posts implanted in the grafted bone), it will be difficult to re-establish the normal transfer of load from muscles to mandible to teeth and from teeth to the mandible (i.e., crown to post to mandible) during chewing without significant loading changes brought about by the immobilization hardware (i.e., both stress shielding and stress concentrations at new locations).

The mandible is generally subjected to two types of loading, muscle forces and bite forces. The masseter, temporalis, and pterygoid muscles are the most important muscles providing positioning and force for jaw closure during mastication. The masseter, temporalis, and medial pterygoid muscles all aid in elevating the mandible. The lateral pterygoid muscle protrudes the mandible during the grinding of food, while the posterior temporalis muscle retracts the mandible. These muscles maintain their tone even when the mandible is at rest. The amount of muscle force applied during chewing depends on many factors including food hardness, occlusion state (repositioning or chewing), biteloading conditions (balanced or unbalanced loading, bilateral or unilateral loading, grinding, or clenching), and the location of the teeth which are relative to the muscles and the 
balancing side jaw joint [121-123]. Hence, mastication is a complicated process involving motion of the mandible in multiple directions. Stress shielding of the bone may result from the high modulus of metallic plates and screws. This stiffness mismatch leads to an uneven load sharing (stress distribution) between the implanted device, grafted bone, and the host mandible. The eventual result may be weakening of the implanted bone and dental implant device loosening, displacement, and failure [124, 125].

Implant geometry can significantly affect the distribution of stresses on the bones surrounding the implant. The area of bone-graft interface and the diameter of the graft are two design factors which affect stress distribution along the reconstructed mandible [126]. Topological optimization of any artificial components used to repair a mandibular segmental defect can also play a crucial role [127]. One of the goals in the reconstruction procedure is to try to have equal graft and host bone cross sectional area at the host-implant interface in order to produce an appropriate profile of stress and mitigate stress concentration [118]. The areas of high and low stress concentrations can be studied by finite element analysis (FEA). Based on the result of the FEA simulation, high stress areas of the grafted bone and implant may be thickened and fixation hardware in areas of low stress may be reduced in size or stiffness to reduce the possibility for stress shielding [128].

\subsection{Infection of a mandibular implant}

As mentioned in Sect. 3.3, infection is another issue of concern when implants are used. This is one reason to consider removing rigid plates, semi-rigid meshes, and screws after an adequate period of bone healing [129]. The benefits of fixation device removal must be balanced against the possible adverse consequences of unfavourable alterations of facial contour and possible interruption of vascular supply to the underlying area of reconstruction [130]. It is not mandatory to remove these devices $[102,110,130,131]$. For mandibular procedures, only $2 \%$ of titanium mesh [109] implants require removal, while titanium plates are removed $17 \%$ of the time following reconstruction for trauma and $7 \%$ of the time following orthognathic reconstruction [110]. Removal of the semirigid mesh panels commonly used for mandible reconstruction is much more difficult than removal of a rigid plate. This is due to connective tissue growth around and through the lattice structure of the mesh panel.

\subsection{Muscle re-attachment during mandibular segmental defect repair}

Another potential limitation for mandibular reconstruction is muscle re-attachment. Incision, mastication (chewing), and speech, are functions that require stable muscle attachment to move the mandible. Often the masticatory muscles (i.e., temporalis, pterygoid, and masseter muscles) will be detached from the bone either because of the original process leading to bone loss or because bone is lost during surgical reconstruction. Full functional restoration depends upon successfully reattaching the muscles to grafted bone or metallic implants. For example, when a segmental defect involves the angle and/or the coronoid process of the mandible, reconstruction requires that all the muscles be detached from the mandibular ramus. The likelihood of reattachment is increased if the bone can be removed and reconstructed with preservation of the periosteum (i.e., the soft tissue superficially investing the bone) through which the muscle attachments pass to reach the underlying cortical bone. Failure for these muscles to re-attach to host bone or to grafted bone is possible; in these cases secondary re-attachment is often successful [132]. In many cases the muscles can be merely re-approximated [133], while in other cases they are sutured, with the sutures sometimes being attached to bone-anchored plates and screws [134]. Wang et al. [135] used Raman spectroscopy to study the reattachment of muscles to grafted bone in a dog model. If the muscles are not successfully re-approximated, there is concern that re-attached masticatory muscles may undergo functional degradation through functional shortening [133], damage, or disuse atrophy [136], thereby making it difficult to restore chewing, breathing, swallowing, and speech.

Muscle reattachment to porous NiTi has been demonstrated as well. Rhalmi et al. [137] used scanning electron microscopy to study biocompatibility of porous NiTi in both bone and muscle in a rabbit model. Muscular implants showed incorporation into the muscular tissue in as little as 3 weeks and continued attachment strength up to 12 weeks. A fine fibrous capsule developed around the implant rapidly indicating quick integration and high biocompatibility. By 3 weeks fibrous material had penetrated all pores and by 12 weeks no fibrous encapsulation was seen, indicating long-term biocompatibility. Muscle tissue fibers at the implant junction oriented themselves towards the pores of the implant. Control of pore orientation in NiTi implants may therefore aid in soft-tissue integration. By 12 weeks organized connective tissue bundles integrated between muscle fascicles were also seen at the implant junction resulting in greater reattachment strength of the muscle.

\section{Discussion and conclusions}

Mandibular defects caused by bone loss may create disability in speech, mastication, swallowing, and breathing as well as disfigurement in personal appearance that can be 
devastating. There are a variety of reconstructive methods that are described for restoring mandibular bone and improving function. These are based on some combination of implanted devices and bone tissue transfer. The simplest approach is to replace the missing bone with a metallic implant that bridges the segmental gap. For the most extensive defects, autologous vascularized bone transfer using microvascular surgical technique is the most reliable method for repair. In all cases, in order to hold the bone in place, rigid plates or semi-rigid mesh are used to immobilize the transferred bone during the healing process. Broadly speaking, the current problems associated with bone reconstruction fall into the following categories: stress shielding, stress concentration, corrosion and toxicity risk, infection, and muscle re-attachment. Muscle and bite forces are the two main types of forces that act on the mandible. They have to be shared appropriately between the mandible, implants (e.g., plates or mesh, bone graft, bone screws), and teeth. However, the high stiffness mismatch of current metal implants and immobilization hardware versus the adjacent host tissue may lead to abnormal stress-strain trajectories which cause stress shielding and stress concentrations. Loss of density occurs around implant regions that stress shield and may even result in subsequent implant failure. Similarly, abnormal stress concentrations may damage adjacent host structures or lead to fixation screw pull-out. Porous NiTi and resorbable $\mathrm{Mg}$-based alloys are promising implant materials due to their low stiffness, which can be tuned to match that of host bone (see Sects. 4 and 5 in Part I of this paper [1, 17, 139-144]). In addition to functional requirements, adequate geometry for a mandibular implant can also help in aesthetic restoration.

Metallic implant corrosion may be associated with an allergic response, cytotoxicity or genotoxicity due to ion release. However, many Ti alloys, including NiTi, have been shown to be biocompatible. The level of $\mathrm{Ni}^{+}$release from SLM-rendered porous NiTi alloys is not associated with toxicity. Current surface treatments insure that a passivation oxide layer is not damaged under physiological loading conditions. Commonly used NiTi implant surface treatments include: thermal annealing, plasma ion immersion implantation (PIII), plasma vapor deposition (PVD), chemical treatments, the PIII method followed by chemical treatment, and in situ nitriding. It should be noted that viable chemical surface modifications are critical for porous devices as submersion techniques can insure that all surfaces exposed to interstitial fluid within the patient have been treated.

Infection of metal implants is caused by colonization of bacteria on the surface of the implant. The potential for bacteria to colonize a porous NiTi implant (i.e., one with greater surface area) is higher compared to non-porous devices. Removal of infected metallic hardware is mandatory. The removal of implanted mesh is more difficult than solid plates due to connective tissue growth around and through the mesh panel. However, the incidence of cases requiring mesh hardware removal is small ( $2 \%$ ) compared to that of plate hardware removal (i.e., $17 \%$ trauma, $7 \%$ orthognathic). Elective non-urgent (planned) removal of metallic implants is desirable to decrease stress shielding. Stress shielding caused by this hardware from mandibular segmental defects can be associated with the loss of normal facial contour and may disrupt the vascular supply of the underlying bone graft. In the future, resorbable fixation implants may also offer a new solution to this problem. Another issue that is specific to mandibular segmental defect reconstruction is detachment of the surrounding masticatory muscles and their entheses when the resection site includes the angle and/or coronoid process of the mandible. Muscle reattachment is usually uneventful, but is of great importance to the restoration of mandibular function.

The safety and potential utility of porous NiTi and magnesium alloy metallic implants for reconstructive surgical immobilization hardware has been confirmed, however neither has been translated to the clinic for use in mandibular reconstruction. In vivo and in vitro studies have reported that bone ingrowth and osseointegration in porous NiTi implants are higher than with solid, non-porous NiTi and solid, nonporous or porous Ti-6Al-4V implants. The three primary reasons cited for this observation are as follows: (1) Porous NiTi implants provide adequate pore size and high void volume. This space is available for bone infilling. (2) Pore interconnectivity and superelasticity of NiTi give the implant pump-like, capillary properties which facilitates absorption of the surrounding fluid. (3) Porous NiTi implants are more bioactive and can have a modulus closer to the surrounding host tissue than solid, non-porous NiTi implants.

Acknowledgments The authors wish to acknowledge partial support for this research from Third Frontier (State of Ohio) grant 15-791, titled "Additive Manufacture of Stiffness-Matched Skeletal Fixation Hardware", to ME and DD.

\section{References}

1. Andani MT, Shayesteh Moghaddam N, Haberland C, Dean D, Miller MJ, Elahinia M (2014) Metals for bone implants. Part 1. Powder metallurgy and implant rendering. Acta Biomater 10(10):4058-4070

2. Nair LS, Laurencin CT (2007) Biodegradable polymers as biomaterials. Prog Polym Sci 32:762-798

3. Jacobs JJ, Gilbert JL, Urban RM (1998) Current concepts review-corrosion of metal orthopaedic implants. J Bone Joint Surg 80:268-282

4. Han H-S, Minghui Y, Seok H-K, Byun J-Y, Cha P-R, Yang S-J, Kim YC (2013) The modification of microstructure to improve 
the biodegradation and mechanical properties of a biodegradable Mg alloy. J Mech Behav Biomed Mater 20:54-60

5. Staiger MP, Pietak AM, Huadmai J, Dias G (2006) Magnesium and its alloys as orthopedic biomaterials: a review. Biomaterials 27:1728-1734

6. Witte F, Feyerabend F, Maier P, Fischer J, Störmer M, Blawert C, Dietzel W, Hort N (2007) Biodegradable magnesium-hydroxyapatite metal matrix composites. Biomaterials 28:21632174

7. Shayesteh Moghaddam N (2015) Toward patient specific long lasting metallic implants for mandibular segmental defects. University of Toledo, Toledo, USA

8. Gu X, Zheng Y, Cheng Y, Zhong S, Xi T (2009) In vitro corrosion and biocompatibility of binary magnesium alloys. Biomaterials 30:484-498

9. Binyamin G, Shafi BM, Mery CM (2006) Biomaterials: a primer for surgeons. Semin Pediatr Surg 15(4):276-283

10. Jacobs JJ, Gilbert JL, Urban RM (1998) Current concepts review-corrosion of metal orthopaedic implants. J Bone Joint Surg Am 80:268-282

11. Jacobs JJ, Gilbert JL, Urban RM (1998) Current concepts review-corrosion of metal orthopaedic implants. J Bone Joint Surg Am 80(2):268-282

12. Shannon C, Thull R, Von Recum A (1997) Types I and III collagen in the tissue capsules of titanium and stainless-steel implants. J Biomed Mater Res 34:401-408

13. Poinern GEJ, Brundavanam S, Fawcett D (2012) Biomedical magnesium alloys: a review of material properties, surface modifications and potential as a biodegradable orthopaedic implant. Am J Biomed Eng 2:218-240

14. Jinno T, Goldberg VM, Davy D, Stevenson S (1998) Osseointegration of surface-blasted implants made of titanium alloy and cobalt-chromium alloy in a rabbit intramedullary model. J Biomed Mater Res 42:20-29

15. Williams DF (2008) On the mechanisms of biocompatibility. Biomaterials 29:2941-2953

16. Dean D, Mott E, Wang M, Moghaddam NS, Taheri Andani M, Fisher J, Elahinia M, Miller M (2014) Tuning the material properties of 3D printed regenerative bone implants. MARY ANN LIEBERT, INC 140 HUGUENOT STREET, 3RD FL, NEW ROCHELLE, NY 10801 USA

17. Shayesteh Moghaddam NS, Skoracki R, Miller M, Elahinia M, Dean D (2016) Three dimensional printing of stiffness-tuned, nitinol skeletal fixation hardware with an example of mandibular segmental defect repair. Proc CIRP 49:45-50

18. Maitz MF, Shevchenko N (2006) Plasma-immersion ion-implanted nitinol surface with depressed nickel concentration for implants in blood. J Biomed Mater Res, Part A 76:356-365

19. Shabalovskaya S, Anderegg J, Van Humbeeck J (2008) Critical overview of Nitinol surfaces and their modifications for medical applications. Acta Biomater 4:447-467

20. Van Rietbergen B, Huiskes R, Weinans H, Sumner D, Turner T, Galante J (1993) The mechanism of bone remodeling and resorption around press-fitted THA stems. J Biomech 26:369-382

21. Kujala S, Ryhänen J, Danilov A, Tuukkanen J (2003) Effect of porosity on the osteointegration and bone ingrowth of a weightbearing nickel-titanium bone graft substitute. Biomaterials 24:4691-4697

22. Zhu S, Yang X, Chen M, Li C, Cui Z (2008) Effect of porous NiTi alloy on bone formation: a comparative investigation with bulk NiTi alloy for 15 weeks in vivo. Mater Sci Eng C Mater Biol Appl 28:1271-1275

23. Kujala S (2003) Biocompatibility and biomechanical aspects of Nitinol shape memory metal implants. University of Oulu, Oulu, Finland
24. Burke D, Bragdon C, O'connor D, Jasty M, Haire T, Harris W (1991) Dynamic measurement of interface mechanics in vivo and the effect of micromotion on bone ingrowth into a porous surface device under controlled loads in vivo. Trans ORS 163:103

25. Branemark PI (1977) Osseointegrated implants in the treatment of edentulous jaw, experience from a 10 -year period. Scand J Plast Reconstr Surg 1:1-132

26. Assad M, Jarzem P, Leroux MA, Coillard C, Chernyshov AV, Charette S, Rivard CH (2003) Porous titanium-nickel for intervertebral fusion in a sheep model: part 1 . Histomorphometric and radiological analysis1. J Biomed Mater Res Part B Appl Biomater 64:107-120

27. Habijan T, Haberland C, Meier H, Frenzel J, Wittsiepe J, Wuwer C, Greulich C, Schildhauer T, Köller M (2012) The biocompatibility of dense and porous nickel-titanium produced by selective laser melting, Materials Science and Engineering. C Mater Biol Appl 33(1):419-426

28. Liu X, Wu S, Yeung KW, Chan Y, Hu T, Xu Z, Liu X, Chung JC, Cheung K, Chu PK (2011) Relationship between osseointegration and superelastic biomechanics in porous NiTi scaffolds. Biomaterials 32:330-338

29. Kang S-B, Yoon K-S, Kim J-S, Nam T-H, Gjunter VE (2002) In vivo result of porous $\mathrm{TiNi}$ shape memory alloy: bone response and growth. Mater Trans 43:1045-1048

30. Rahmanian R, Shayesteh Moghaddam N, Haberland C, Dean D, Miller M, Elahinia M (2014) Load bearing and stiffness tailored NiTi implants produced by additive manufacturing: a simulation study. The International Society for Optical Engineering, San Diego

31. Li Y-H, Rao G-B, Rong L-J, Li Y-Y (2002) The influence of porosity on corrosion characteristics of porous NiTi alloy in simulated body fluid. Mater Lett 57:448-451

32. Li B-Y, Rong L-J, Li Y-Y (2000) Stress-strain behavior of porous $\mathrm{Ni}-\mathrm{Ti}$ shape memory intermetallics synthesized from powder sintering. Intermetallics 8:643-646

33. Hernandez R, Polizu S, Turenne S, Yahia LH (2002) Characteristics of porous nickel-titanium alloys for medical applications. Biomed Mater Eng 12:37-45

34. Chu C, Chung C, Lin P, Wang S (2004) Fabrication of porous NiTi shape memory alloy for hard tissue implants by combustion synthesis. Mater Sci Eng A 366:114-119

35. Chen S, Guan S, Li W, Wang H, Chen J, Wang Y, Wang H (2012) In vivo degradation and bone response of a composite coating on $\mathrm{Mg}-\mathrm{Zn}-\mathrm{Ca}$ alloy prepared by microarc oxidation and electrochemical deposition. J Biomed Mater Res Part B Appl Biomater 100:533-543

36. Kunchur MN, Dean CL, Moghadam NS, Knight JM, He Q, Liu H, Wang J, Lortz R, Sou I, Gurevich A (2015) Current-induced depairing in the Bi 2 Te 3/FeTe interfacial superconductor. Phys Rev B 92:094502

37. Kunchur MN, Dean C, Liang M, Moghaddam NS, Guarino A, Nigro A, Grimaldi G, Leo A (2013) Depairing current density of $\mathrm{Nd} 2-\mathrm{x} \mathrm{Ce} \times \mathrm{CuO} 4-\delta$ superconducting films. Phys $\mathrm{C}$ 495:66-68

38. Rahmani M, Ahmadi MT, Shayesteh N, Amin NA, Rahmani K, Ismail R (2011) Current-voltage modeling of bilayer graphene nanoribbon schottky diode. Micro and nanoelectronics (RSM), 2011 IEEE Regional Symposium on: IEEE, pp 256-258

39. Li Z, Gu X, Lou S, Zheng Y (2008) The development of binary $\mathrm{Mg}-\mathrm{Ca}$ alloys for use as biodegradable materials within bone. Biomaterials 29:1329-1344

40. Denkena B, Meyer-Lindenberg A, Lucas A, Thorey F, Waizy H, Angrisani N (2011) Biocompatible magnesium alloys as degradable implant materials-Machining induced surface and 
subsurface properties and implant performance. INTECH Open Access Publisher. ISBN: 9789533073910

41. Höh NVD, Bormann D, Lucas A, Denkena B, Hackenbroich C, Meyer-Lindenberg A (2009) Influence of different surface machining treatments of magnesium-based resorbable implants on the degradation behavior in rabbits. Adv Eng Mater 11:B47B54

42. Rahmani M, Ahmadi M, Webb J, Shayesteh N, Mousavi S, Sadeghi H, Ismail R (2012) Trilayer graphene nanoribbon carrier statistics in degenerate and non degenerate limits. In: Proceedings of the sixth global conference on power control and optimization, vol. 1499: AIP Publishing, pp 272-275

43. Moghaddam N, Ahmadi M, Webb J, Rahmani M, Sadegi H, Musavi M, Ismail R (2012) Modeling of graphene nano-ribbon Schottky diodes in the parabolic band structure limit. In: Proceedings of the sixth global conference on power control and optimization, vol. 1499: AIP Publishing, pp 268-271

44. Moghaddam NS, Ahmadi MT, Rahmani M, Amin NA, Moghaddam HS, Ismail R (2011) Monolayer graphene nanoribbon pn junction. Micro and Nanoelectronics (RSM), 2011 IEEE Regional Symposium on: IEEE, pp 253-255

45. Jethanandani R (1997) The development and application of diamond-like carbon films. JOM 49:63-65

46. Diplas S, Tsakiropoulos P, Brydson R (1999) Development of physical vapour deposited $\mathrm{Mg}-\mathrm{Zr}$ alloys Part 1-Characterisation of as deposited alloys. Mater Sci Technol 15:1349-1357

47. Dodd S, Morris S, Gardiner R, Brydson R, Diplas S, Tsakiropoulos P (1998) Preliminary corrosion evaluation of some novel bulk electron beam evaporated magnesium alloys. Corros Rev 16:159-174

48. Elahinia M, Moghaddam NS, Andani MT, Skoracki R, Valerio I, Miller M, Dean D (2015) Mitigating implant failure through design and manufacturing of nitinol fixation hardware. Tissue engineering part A, vol. 21: Mary Ann Liebert, Inc 140 huguenot street, 3rd fl, New Rochelle, NY 10801 USA, pp S10-S10

49. Joshi MG, Advani SG, Miller F, Santare MH (2000) Analysis of a femoral hip prosthesis designed to reduce stress shielding. J Biomech 33:1655-1662

50. Nagels J, Stokdijk M, Rozing PM (2003) Stress shielding and bone resorption in shoulder arthroplasty. J Shoulder Elbow Surg 12:35-39

51. Bahraminasab M, Sahari B, Edwards K, Farahmand F, Arumugam M, Hong TS (2012) Aseptic loosening of femoral components-a review of current and future trends in materials used. Mater Des 42:459-470

52. Shayesteh Moghaddam N, Elahinia M, Miller M, Dean D (2014) Enhancement of bone implants by substituting nitonol for titanium (TI-6AL-4V): a modeling comparison. ASME 2014 conference on smart materials, adaptive structures and intelligent systems. Newport, Rhoad Island

53. Hadi A, Qasemi M, Elahinia M, Moghaddam N (2014) Modeling and experiment of a flexible module actuated by shape memory alloy wire. ASME 2014 conference on smart materials, adaptive structures and intelligent systems: American Society of Mechanical Engineers, pp V001T003A035-V001T003A035

54. Katz JN, Wright EA, Wright J, Malchau H, Mahomed NN, Stedman M, Baron JA, Losina E (2012) Twelve-year risk of revision after primary total hip replacement in the US Medicare population. J Bone Joint Surg 94:1825-1832

55. Esfahani SN, Andani MT, Moghaddam NS, Mirzaeifar R, Elahinia M (2016) Independent tuning of stiffness and toughness of additively manufactured titanium-polymer composites: simulation, fabrication, and experimental studies. J Mater Process Technol 238:22-29

56. Raad B, Moghaddam NS, Elahinia M (2016) A numerical simulation of the effect of using porous superelastic Nitinol and stiff Titanium fixation hardware on the bone remodeling. SPIE smart structures and materials + nondestructive evaluation and health monitoring: international society for optics and photonics, p 98021T-98021T-98029

57. Urban RM, Jacobs JJ, Sumner DR, Peters CL, Voss FR, Galante JO (1996) The bone-implant interface of femoral stems with non-circumferential porous coating. A study of specimens retrieved at autopsy. J Bone Joint Surg 78:1068-1081

58. Shabalovskaya SA (1996) On the nature of the biocompatibility and on medical applications of $\mathrm{NiTi}$ shape memory and superelastic alloys. Biomed Mater Eng 6:267-289

59. Blackwood D (2003) Biomaterials: past successes and future problems. Corros Rev 21:97-124

60. Liu X, Chu PK, Ding C (2004) Surface modification of titanium, titanium alloys, and related materials for biomedical applications. Mater Sci Eng R Rep 47:49-121

61. Jones LC, Hungerford DS (1987) Cement disease. Clin Orthop Relat Res 225:192-206

62. Greiner C, Oppenheimer SM, Dunand DC (2005) High strength, low stiffness, porous $\mathrm{NiTi}$ with superelastic properties. Acta Biomater 1:705-716

63. Elahinia MH, Hashemi M, Tabesh M, Bhaduri SB (2012) Manufacturing and processing of NiTi implants: a review. Prog Mater Sci 57:911-946

64. Okazaki Y, Gotoh E (2005) Comparison of metal release from various metallic biomaterials in vitro. Biomaterials 26:11-21

65. McGregor D, Baan R, Partensky C, Rice J, Wilbourn J (2000) Evaluation of the carcinogenic risks to humans associated with surgical implants and other foreign bodies-a report of an IARC monographs programme meeting. Eur J Cancer 36:307-313

66. Batmanghelich F, Ghorbani M (2013) Effect of $\mathrm{pH}$ and carbon nanotube content on the corrosion behavior of electrophoretically deposited chitosan-hydroxyapatite-carbon nanotube composite coatings. Ceram Int 39:5393-5402

67. Ng KW (2009) Enhancement of biocompatibility of nickel-titanium by laser surface modification technology. The Hong Kong Polytechnic University, Hong Kong

68. Rosu RA, Bran I, Popescu M, Opris C (2012) In vitro characterisation of hydroxyapatite layers deposited by aps and hvof thermal spraying methods. Ceram Silik 56:25-31

69. Wever D, Veldhuizen A, Sanders M, Schakenraad J, Van Horn J (1997) Cytotoxic, allergic and genotoxic activity of a nickeltitanium alloy. Biomaterials 18:1115-1120

70. Li H, Yuan B, Gao Y, Chung C, Zhu M (2011) Remarkable biocompatibility enhancement of porous NiTi alloys by a new surface modification approach: in-situ nitriding and in vitro and in vivo evaluation. J Biomed Mater Res Part A 99:544-553

71. Ho J, Wu S, Poon R, Chung C, Tjong S, Chu P, Yeung K, Lu W, Cheung K, Luk K (2007) Oxygen plasma treatment to restrain nickel out-diffusion from porous nickel titanium orthopedic materials. Surf Coat Technol 201:4893-4896

72. Jiang H, Rong L (2006) Effect of hydroxyapatite coating on nickel release of the porous NiTi shape memory alloy fabricated by SHS method. Surf Coat Technol 201:1017-1021

73. Yuan B, Li H, Gao Y, Chung C, Zhu M (2009) Passivation and oxygen ion implantation double surface treatment on porous $\mathrm{NiTi}$ shape memory alloys and its $\mathrm{Ni}$ suppression performance. Surf Coat Technol 204:58-63

74. Bernard SA, Balla VK, Davies NM, Bose S, Bandyopadhyay A (2011) Bone cell-materials interactions and $\mathrm{Ni}$ ion release of anodized equiatomic NiTi alloy. Acta Biomater 7:1902-1912

75. Wu S, Liu X, Chan Y, Chu PK, Chung C, Chu C, Yeung KW, Lu W, Cheung K, Luk K (2009) Nickel release behavior and surface characteristics of porous NiTi shape memory alloy modified by different chemical processes. J Biomed Mater Res Part A 89:483-489 
76. Mändl S, Rauschenbach B (2002) Improving the biocompatibility of medical implants with plasma immersion ion implantation. Surf Coat Technol 156:276-283

77. Poon RW, Ho JP, Liu X, Chung C, Chu PK, Yeung KW, Lu WW, Cheung K (2005) Anti-corrosion performance of oxidized and oxygen plasma-implanted NiTi alloys. Mater Sci Eng A 390:444-451

78. Lemaire V, Sicotte B, Allard S (2008) Surface modification treatments to reduce Ni leaching from porous nitinol. In: Proceedings of 5th International Conference on porous metals and metallic foams: DEStech Publications, Inc,. p 291

79. Wu S, Liu X, Chan Y, Chung C, Chu PK, Chu C, Lam K, Yeung $\mathrm{K}, \mathrm{Lu} \mathrm{W}$, Luk K (2008) In vitro bioactivity and osteoblast response on chemically modified biomedical porous NiTi synthesized by capsule-free hot isostatic pressing. Surf Coat Technol 202:2458-2462

80. Wu S, Liu X, Chung C, Chu PK, Chan Y, Yeung K, Chu C (2008) Biomimetic deposition of apatite on surface chemically modified porous NiTi shapememory alloy. Surf Rev Lett 15:97-104

81. Bidabadi M, Natanzi AHA, Mostafavi SA (2012) Thermophoresis effect on volatile particle concentration in microorganic dust flame. Powder Technol 217:69-76

82. Bansiddhi A, Sargeant T, Stupp S, Dunand D (2008) Porous NiTi for bone implants: a review. Acta Biomater 4:773-782

83. Puckett SD, Taylor E, Raimondo T, Webster TJ (2010) The relationship between the nanostructure of titanium surfaces and bacterial attachment. Biomaterials 31:706-713

84. Schmidt AH, Swiontkowski MF (2000) Pathophysiology of infections after internal fixation of fractures. J Am Acad Orthop Surg 8:285-291

85. Kuijer R, Jansen EJ, Emans PJ, Bulstra SK, Riesle J, Pieper J, Grainger DW, Busscher HJ (2007) Assessing infection risk in implanted tissue-engineered devices. Biomaterials 28:5148-5154

86. Niechajev I (1999) Porous polyethylene implants for nasal reconstruction: clinical and histologic studies. Aesthet Plast Surg 23:395-402

87. Gasik M, Van Mellaert L, Pierron D, Braem A, Hofmans D, De Waelheyns E, Anné J, Harmand MF, Vleugels J (2012) Reduction of biofilm infection risks and promotion of osteointegration for optimized surfaces of titanium implants. Adv Healthc Mater 1:117-127

88. Mendonça G, Mendonca D, Aragao FJ, Cooper LF (2008) Advancing dental implant surface technology-from micron-to nanotopography. Biomaterials 29:3822-3835

89. Harris LG, Richards RG (2006) Staphylococci and implant surfaces: a review. Injury 37:S3-S14

90. Wu Y, Zitelli JP, TenHuisen KS, Yu X, Libera MR (2011) Differential response of Staphylococci and osteoblasts to varying titanium surface roughness. Biomaterials 32:951-960

91. Cochran D, Schenk R, Lussi A, Higginbottom F, Buser D (1998) Bone response to unloaded and loaded titanium implants with a sandblasted and acid-etched surface: a histometric study in the canine mandible. J Biomed Mater Res 40:1-11

92. Wennerberg A, Hallgren C, Johansson C, Danelli S (1998) A histomorphometric evaluation of screw-shaped implants each prepared with two surface roughnesses. Clin Oral Implant Res 9:11-19

93. Wong M, Eulenberger J, Schenk R, Hunziker E (1995) Effect of surface topology on the osseointegration of implant materials in trabecular bone. J Biomed Mater Res 29:1567-1575

94. Martin J, Schwartz Z, Hummert T, Schraub D, Simpson J, Lankford J, Dean D, Cochran D, Boyan B (1995) Effect of titanium surface roughness on proliferation, differentiation, and protein synthesis of human osteoblast-like cells (MG63). J Biomed Mater Res 29:389-401
95. Branemark P-I (1983) Osseointegration and its experimental background. J Prosthet Dent 50:399-410

96. Buser D, Nydegger T, Hirt HP, Cochran DL, Nolte LP (1998) Removal torque values of titanium implants in the maxilla of miniature pigs. Int J Oral Maxillofac Implant 13(5):611-619

97. Elias CN, Oshida Y, Lima JHC, Muller CA (2008) Relationship between surface properties (roughness, wettability and morphology) of titanium and dental implant removal torque. J Mech Behav Biomed Mater 1:234-242

98. Albrektsson T, Wennerberg A (2004) Oral implant surfaces: part 1 -review focusing on topographic and chemical properties of different surfaces and in vivo responses to them. Int J Prosthodont 17(5):536-543

99. Macak J, Tsuchiya H, Ghicov A, Yasuda K, Hahn R, Bauer S, Schmuki P (2007) TiO 2 nanotubes: self-organized electrochemical formation, properties and applications. Curr Opin Solid State Mater Sci 11:3-18

100. Boyan BD, Dean DD, Lohmann CH, Cochran DL, Sylvia VL, Schwartz Z (2001) The titanium-bone cell interface in vitro: the role of the surface in promoting osteointegration. Titanium in medicine. Springer, Berlin, pp 561-585

101. Moghaddam NS, Jahadakbar A, Elahinia M, Dean D, Miller M (2015) The effect of adding dental implants to the reconstructed mandible comparing the effect of using Ti-6al-4v and Niti hardware. Tissue engineering part A, vol. 21: Mary ANN LIEBERT, INC 140 HUGUENOT STREET, 3RD FL, NEW ROCHELLE, NY 10801 USA, pp S398-S398

102. Abbas A (2012) Reconstruction skeleton for the lower human jaw using CAD/CAM/CAE. J King Saud Univ Eng Sci 24:159-164

103. Elahinia M, Moghaddam NS, Andani MT, Rahmanian R, Walker J, Miller M, Dean D (2014) Site-specific material properties and the additive manufacturing of nitinol musculoskeletal implants. Tissue engineering part A, vol. 20: Mary Ann Liebert, Inc 140 huguenot street, 3rd fl, New Rochelle, NY 10801 USA, pp S120-S121

104. Azuma M, Yanagawa T, Ishibashi-Kanno N, Uchida F, Ito T, Yamagata K, Hasegawa S, Sasaki K, Adachi K, Tabuchi K, Sekido M, Bukawa H (2014) Mandibular reconstruction using plates prebent to fit rapid prototyping 3-dimensional printing models ameliorates contour deformity. Head face Med 10(1):1-8

105. Walker J, Andani MT, Haberland C, Elahinia M (2014) Additive manufacturing of nitinol shape memory alloys to overcome challenges in conventional nitinol fabrication. In: ASME 2014 international mechanical engineering congress and exposition: American Society of Mechanical Engineers, p V02AT02A037V002AT002A037

106. Andani MT, Haberland C, Walker J, Elahinia M (2014) An investigation of effective process parameters on phase transformation temperature of nitinol manufactured by selective laser melting. In: ASME 2014 conference on smart materials, adaptive structures and intelligent systems: American Society of Mechanical Engineers, p V001T001A026-V001T001A026

107. Shirani M, Mehrabi R, Andani MT, Kadkhodaei M, Elahinia M, Andani MT (2014) A modified microplane model using transformation surfaces to consider loading history on phase transition in shape memory alloys. In: ASME 2014 conference on smart materials, adaptive structures and intelligent systems: American Society of Mechanical Engineers, p V001T001A001V001T001A001

108. Rahmanian R, Andani MT, Walker J, Habeland C, Elahinia M, Dean D, Miller M (2014) Modeling and validation of additively manufactured porous nitinol implants. In: ASME 2014 conference on smart materials, adaptive structures and intelligent systems: American Society of Mechanical Engineers, $p$ V001T003A032-V001T003A032 
109. Dérand P, Rännar L-E, Hirsch J-M (2012) Imaging, virtual planning, design, and production of patient-specific implants and clinical validation in craniomaxillofacial surgery. J Cranio Maxilofac Surg 5:137

110. Lazaridis N, Makos C, Iordanidis S, Zouloumis L (1998) The use of titanium mesh sheet in the frontozygma tico-orbital region. Case Rep Aust Dent J 43:223-228

111. Tsuchiya S, Nakatsuka T, Sakuraba M, Kimata Y, Sakurai H, Nakagawa M, Takushima A (2013) Clinical factors associated with postoperative complications and the functional outcome in mandibular reconstruction. Microsurgery 33:337-341

112. Cohen A, Laviv A, Berman P, Nashef R, Abu-Tair J (2009) Mandibular reconstruction using stereolithographic 3-dimensional printing modeling technology. Oral Surg Oral Med Oral Pathol Oral Radiol Endodontol 108:661-666

113. Hidalgo DA, Pusic AL, Wei F-C (2002) Free-flap mandibular reconstruction: a 10-year follow-up study. Plast Reconstr Surg 110:438-449

114. Goh BT, Lee S, Tideman H, Stoelinga PJ (2008) Mandibular reconstruction in adults: a review. Int J Oral Maxillofac Surg 37:597-605

115. Gregory G, Gavin D (2000) Improving the mandibular reconstruction plate: technical innovation. J R Coll Surg Edinb 45:120-121

116. Hayden RE, Mullin DP, Patel AK (2012) Reconstruction of the segmental mandibular defect: current state of the art. Curr Opin Otolaryngol Head Neck Surg 20:231-236

117. Wong R, Tideman H, Kin L, Merkx M (2010) Biomechanics of mandibular reconstruction: a review. Int J Oral Maxillofac Surg 39:313-319

118. Tie Y, Wang DM, Ji T, Wang CT, Zhang CP (2006) Threedimensional finite-element analysis investigating the biomechanical effects of human mandibular reconstruction with autogenous bone grafts. J Cranio Maxilofac Surg 34:290-298

119. Burkey BB, Coleman JR Jr (1997) Current concepts in oromandibular reconstruction. Otolaryngol Clin North Am 30:607-630

120. Kennady MC, Tucker MR, Lester GE, Buckley MJ (1989) Histomorphometric evaluation of stress shielding in mandibular continuity defects treated with rigid fixation plates and bone grafts. Int J Oral Maxillofac Surg 18:170-174

121. Tanaka E, Koolstra J (2008) Biomechanics of the temporomandibular joint. J Dent Res 87:989-991

122. Kavanagh E, Frawley C, Kearns G, Wallis F, McGloughlin T, Jarvis J (2008) Use of finite element analysis in presurgical planning: treatment of mandibular fractures. Ir J Med Sci 177:325-331

123. Moghaddam N, Jahadakbar A, Amerinatanzi A, Elahinia M, Miller M, Dean D (2016) Metallic fixation of mandibular segmental defects: graft immobilization and orofacial functional maintenance, plastic and reconstructive surgery-global open. doi:10.1097/GOX.0000000000000859

124. Keller EE, Tolman D, Eckert S (1997) Endosseous implant and autogenous bone graft reconstruction of mandibular discontinuity: a 12-year longitudinal study of 31 patients. Int J Oral Maxillofac Implants 13:767-780

125. Yarlagadda PK, Chandrasekharan M, Shyan JYM (2005) Recent advances and current developments in tissue scaffolding. Biomed Mater Eng 15:159-177

126. Baggi L, Cappelloni I, Di Girolamo M, Maceri F, Vairo G (2008) The influence of implant diameter and length on stress distribution of osseointegrated implants related to crestal bone geometry: a three-dimensional finite element analysis. J Prosthet Dent 100:422-431

127. Sutradhar A, Paulino GH, Miller MJ, Nguyen TH (2010) Topological optimization for designing patient-specific large craniofacial segmental bone replacements. Proc Natl Acad Sci 107:13222-13227

128. Li P, Shen L, Li J, Liang R, Tian W, Tang W (2014) Optimal design of an individual endoprosthesis for the reconstruction of extensive mandibular defects with finite element analysis. J Cranio Maxilofac Surg 42:73-78

129. Murthy AS, Lehman JA Jr (2005) Symptomatic plate removal in maxillofacial trauma: a review of 76 cases. Ann Plast Surg 55:603-607

130. Blackwell KE, Lacombe V (1999) The bridging lateral mandibular reconstruction plate revisited. Arch Otolaryngol Head Neck Surg 125:988-993

131. Yerit KC, Enislidis G, Schopper C, Turhani D, Wanschitz F, Wagner A, Watzinger F, Ewers R (2002) Fixation of mandibular fractures with biodegradable plates and screws. Oral Surg Oral Med Oral Pathol Oral Radiol Endodontol 94:294-300

132. Thomas MA, Yaremchuk MJ (2009) Masseter muscle reattachment after mandibular angle surgery. Aesthet Surg J 29:473-476

133. Choukas NC, Toto PD, Seth VK (1968) The reattachment of the masseter muscle to the mandible. Oral Surg Oral Med Oral Pathol 25:889-895

134. Barone CM, Jimenez DF, Boschert MT (2001) Temporalis muscle resuspension using titanium miniplates and screws: technical note. Neurosurgery 48:450-451

135. Wang L, Su Y-X, Zheng G-S, Liao G-Q, Zhang W-H (2013) Healing masseter entheses of mandibular reconstruction with autograft-Raman spectroscopic and histological study. Int J Oral Maxillofac Surg 42:915-922

136. Pomatto E, Castellano S, Bianchi S (2001) Unilateral fibroadipose degeneration of the masticatory muscles. Dentomaxillofac Radiol 30:346-348

137. Rhalmi S, Odin M, Assad M, Tabrizian M, Rivard CH, Yahia LH (1999) Hard, soft tissue and in vitro cell response to porous nickel-titanium: a biocompatibility evaluation. Biomed Mater Eng 9:151-162

138. Krishna BV, Bose S, Bandyopadhyay A (2007) Laser processing of Net-Shape NiTi shape memory alloy. Metall Mat Trans A 38:1096-1103

139. Elahinia M, Moghaddam NS, Andani MT, Amerinatanzi A, Bimber BA, Hamilton RF (2016) Fabrication of NiTi through additive manufacturing: a review. Prog Mater Sci 83:630-663

140. Ahmadi A, Mirzaeifar R, Moghaddam NS, Turabi AS, Karaca HE, Elahinia M (2016) Effect of manufacturing parameters on mechanical properties of $316 \mathrm{~L}$ stainless steel parts fabricated by selective laser melting: a computational framework. Mater Des. doi:10.1016/j.matdes.2016.09.043

141. Skoracki R, Miller M, Jahadakbar A, Andan MTi, Moghaddam NS, Haberland C, Dean D, Walker J, Karaca H, Elahinia M (2015) Additive manufacturing of nitinol fixation hardware for reconstructing mandibular segmental defects. In: ASM international-international conference on shape memory and superelastic technologies, SMST 2015. ASM International, pp 84-87

142. Ahmadi A, Moghaddam NS, Elahinia M, Karaca HE, Mirzaeifar R (2016) Finite element modeling of selective laser melting $316 \mathrm{~L}$ stainless steel parts for evaluating the mechanical properties. In: ASME 2016 11th international manufacturing science and engineering conference, 27 June 2016. American Society of Mechanical Engineers, pp V002T01A003-V002T01A003

143. Raad B, Moghaddam NS, Elahinia M (2016) A comparison between porous NiTi and Ti-6Al-4V fixation hardware on bone remodeling after a reconstruction surgery. In: ASME 2016 11th international manufacturing science and engineering conference, 27 June 2016. American Society of Mechanical Engineers, pp V002T03A001-V002T03A001 
144. Amerinatanzi A, Moghaddam NS, Jahadakbar A, Dean D, Elahinia M (2016) On the effect of screw preload on the stress distribution of mandibles during segmental defect treatment using an additively manufactured hardware. In: ASME 2016 11th international manufacturing science and engineering conference, 27 June 2016. American Society of Mechanical Engineers, pp V002T03A015-V002T03A015 